\title{
How Do Regenerative Endodontic Procedures Work for Immature Necrotic Teeth?
}

\author{
Su-Min Lee* \\ Department of Endodontics, School of Dental Medicine, University of Pennsylvania, USA
}

*Corresponding author: Su-Min Lee, Department of Endodontics, School of Dental Medicine, University of Pennsylvania. Philadelphia, USA.

Received Date: March 12, 2020

Published Date: April 09, 2020

\begin{abstract}
Treating an immature tooth with necrotic pulp has been a real challenge for dentists. Large immature canals without physiologic apical closure are difficult to debride, and restoring immature teeth with thin dentin walls is a challenge due to the tooth's susceptibility to cervical root fracture. The majority of human case studies have shown good clinical outcomes such as the absence of clinical signs and symptoms, radiographic evidence of resolution of periapical infections, continued root development, and increased canal wall thickness for immature permanent teeth with pulpal necrosis following regenerative endodontic procedures (REPs). Furthermore, REPs have the potential to heal a necrotic pulp and restore functionality. This review compiles information on the principles and clinical protocols of REPs as well as their outcomes.
\end{abstract}

Keywords: Immature tooth; Pulp necrosis; Apexification; Regenerative endodontic procedures; Mesenchymal stem cells; Disinfection; Triple antibiotic paste

Abbreviations: REPs: Regenerative endodontic procedures; MTA: Mineral trioxide aggregate; MSCs: Mesenchymal stem cells; PUI: Passive ultrasonic irrigation; EDTA: Ethylenediaminetetraacetic acid; TAP: Triple antibiotic paste; DAP: Double antibiotic paste

\section{Introduction}

Traumatic injury, pulp exposure with anatomic anomalies such as dens invaginatus or evaginatus, or caries of an immature permanent tooth can cause pulpal necrosis and interrupted root development. The results of arrested root development are a poor crown-root ratio, an open apex, a root with very thin walls, and an increased risk of fracture. Traditionally immature teeth with necrotic pulps have been treated with apexification procedures which include long-term calcium hydroxide $\mathrm{Ca}(\mathrm{OH}) 2$ dressing with multiple visits or one-step apexification with placing an apical plug of a mineral trioxide aggregate (MTA) prior to root canal filling. Even though these treatments often result in the elimination of apical periodontitis and the resolution of clinical signs and symptoms of disease, they do not allow for the thickening of the root canal wall and further root development [1]. Thus, immature teeth remain with thin root canal walls and poor crown-to-root ratios, which increases susceptibility to cervical root fractures and decreases long-term survival rates.
Regenerative endodontic procedures (REPs) have been proposed as better alternative treatments for immature necrotic teeth [2]. REPs induce the revitalization of teeth after removing necrotic pulp tissue. Furthermore, these procedures promote apical closure and the completion of root formation, which leads to a better long-term prognosis. Accumulated evidence on the clinical feasibility of this approach has shown that REPs belong to the endodontic treatment spectrum [3]. Furthermore, this modality has been increasingly accepted as an alternative option for the management of a variety of endodontic situations such as mature teeth, retreatments, cases with root resorption, and cases with large cystic lesions [3-5].

What is the Biological Basis for Regenerative Endodontic Procedures?

Induction of bleeding to facilitate healing is a common practice done in surgical procedures. In REPs of immature permanent teeth with necrotic pulps, induction of periapical bleeding into the canal 
space is the most critical step to achieve treatment goals [2]. Blood clots in the canal space can act as a natural fibrin matrix or scaffold for cell attachment, proliferation, and differentiation in order to facilitate the regeneration and repair of tissues into the canal. Following intentional over-instrumentation into the periapical region, induced periapical bleeding provokes the ingress of mesenchymal stem cells (MSCs) from the apical papilla in immature teeth or from bone marrow of the jaw to the canal space $[3,6]$. Furthermore, blood contains abundant platelet-derived growth factors which will aid in revascularization. Therefore, induced periapical bleeding provides the three essential components for pulp tissue engineering including fibrin scaffold, MSCs, and bloodderived bioactive growth factors [3,7]. In addition, successful regenerated vital tissues in the canal space can most likely mount immune-inflammatory responses and conduct signaling tissue damage by sensory responses, which might kill remaining bacteria in the canal space and improve the long-term survival of teeth.

However, pulp revascularization from this biologically based approach requires an imperative bacteria-free condition. Prior to cell colonization, clean and disinfected root canal system should be achieved [8,9]. Recently, a few case reports have shown the recurrence of periapical lesions and/or suboptimal results such as no apical closure and no additional root formation following REPs. Even though the patients were clinically asymptomatic, their histological analysis revealed that there were remaining bacteria with limited regenerated tissue in the root canal $[10,11]$. Moreover, it is not known to what degree the root canal system needs to be disinfected or which bacterial count needs to be lowered below the threshold level in order for clinical success to be evident. Thus, many translational studies for REPs have been conducted to establish the biological basis for clinical protocols that could achieve adequate disinfection in root canal space with preservation of optimum regenerative potential of MSCs in the periapical region [9].

\section{What are Disinfection Protocols for Regenerative Endodontic Procedures?}

In the case of REPs for immature necrotic teeth, clinicians often face the challenge of effectively facilitating debridement of large infected root canals with wide open apex. The application of the Self-Adjusting File (SAF; Reddens-Nova, Ra'anana, Israel), XPendo shaper (FKG Dentaire SA, La Chaux-de-Fonds, Switzerland) or TRUshaper (Dentsply-Tulsa, Tulsa, OK) could perform 3-D instrumentation in the wide canal space. However, due to fragile thin dentinal walls of these canals, minimal mechanical preparation in REPs should be performed to disrupt biofilm. Thus, the primary form of disinfection in REPs involves mainly irrigant solutions and intracanal medications. Sodium hypochlorite $(\mathrm{NaOCl})$ with concentrations ranging from $2.5 \%$ to $5.25 \%$ is the most widely used agent for chemical debridement in endodontic procedures. While its excellent bactericidal efficacy and tissue dissolution capacity are crucial for the disinfection of immature teeth in REPs, $\mathrm{NaOCl}$ at its maximum clinically used concentration could denature growth factors embedded in the dentin matrix and has a profoundly deleterious effect on MSCs survival [12,13]. Therefore, root canals need to be gently irrigated using $20 \mathrm{ml}$ of $1.5 \% \mathrm{NaOCl}$ with a sidevented irrigation needle for 5 minutes. Irrigation needle should be positioned about $1 \mathrm{~mm}$ from the root end to prevent periapical extrusion of the irrigant, which can damage MSCs in the periapical area. To maximize it's anti-microbial and -biofilm activity in these wide canals, passive ultrasonic irrigation (PUI) or using XP-endo finisher (FKG Dentaire SA) is recommended.

Subsequently, root canals need to be irrigated with $5 \mathrm{ml}$ of sterile physiological saline or $20 \mathrm{ml}$ of $17 \%$ ethylenediaminetetraacetic acid (EDTA) for 5 minutes to minimize the detrimental effects of $\mathrm{NaOCl}$ on vital tissues [14]. In addition, 17\% EDTA not only enhances the survival, differentiation, and attachment of MSCs [15] but promotes the release of bioactive growth factors embedded in the dentin matrix during dentinogenesis. These growth factors actively participate in pulp regenerative processes such as angiogenesis and stem cell proliferation, migration, and differentiation [16]. Therefore, as a final step in the irrigation protocol, root canals need to be irrigated with $17 \%$ EDTA before inducing periapical bleeding with over-instrumentation. However, chlorhexidine may cause other problems when used in REPs, including substantivity and toxicity to stem cells of the apical papilla and the formation of toxic chemicals with the interaction with $\mathrm{NaOCl}$, which are difficult to completely avoid $[12,17]$.

The particular mixture of antibiotics has been suggested to effectively disinfect root canal systems and enhance revascularization of avulsed necrotic teeth. This combination includes metronidazol, ciprofloxacin, and minocycline with a ratio of 1:1:1, known as triple antibiotic paste (TAP) [18]. As minocycline induced tooth discoloration, it has (been?) excluded (double antibiotic paste, DAP) or (been?) replaced with amoxicillin, clindamycin, or cefaclor. These antibiotic powders are mixed with saline or propylene glycol and then form a thick creamy mixture with approximately $1 \mathrm{mg} / \mathrm{ml}$. At this concentration, however, TAP appears to have long-lasting detrimental effects on MSCs survival. Thus, DAP or TAP is recommended to be diluted to $0.01-0.1 \mathrm{mg} /$ $\mathrm{ml}$ which retains the desirable antibacterial effect and avoids stem cell toxicity $[19,20]$. Furthermore, widely available intracanal medicament, calcium hydroxide $\mathrm{Ca}(\mathrm{OH}) 2$ can be used in REPs as its antimicrobial concentrations do not induce stem cell toxicity [19]. However, case reviews have revealed that cases that used $\mathrm{Ca}(\mathrm{OH}) 2$ do not enhance root development compared to the cases that used TAP [21].

\section{What are the Outcomes of Regenerative Endodontic Procedures?}

Numerous published reports demonstrated REPs have offered superior outcomes for the management of immature teeth with necrotic pulp over the traditional treatment, apexification, which leads to the thickening of root canal walls and the promotion of normal physiological root development in addition to the elimination of apical periodontitis [1,3]. Our group's retrospective 
study demonstrated that $75 \%$ of cases (21 of 28 cases) showed successful resolution of apical periodontitis with continued root development. An additional four cases (14\%) presented with periradicular healing during the observation period. However, three failed cases $(11 \%)$ revealed coronal leakage from fractured restoration or inflammatory root resorption within a month from initiating REPs [22]. Furthermore, recent reports have shown there is pulp-like tissue in human teeth that have been extracted following REPs [10,23]. Based on case studies, the healing progression following REPs will vary depending on the initial presentation and variations in protocols. Radiographic evidence of apical healing typically precedes continuation of root formation. However, radiographic evidence of complete apical closure and the maturation of root development may take more than 2 years $[21,22]$. Furthermore, the predictability of complete root formation and the regeneration of a desirable tissue that is similar to native pulp tissue are still uncertain $[3,24]$.

\section{Conclusion}

Regenerative endodontic procedures in which root canal therapy brings diseased teeth back to life rather than leaving a "nonvital" or dead tooth in the oral cavity are revolutionary treatments in dentistry. However, there is still variable predictability of continued root development and inconsistent root development, as well as evidence that the newly formed tissues may not present full root regeneration of the native pulp-dentin complex, but some degree of tissue repair or wound healing. Researchers in the fields of pulp biology, dental trauma and pulp tissue engineering continue to evaluate new approaches to achieve predictable, consistent outcomes in REP. Future research into the development of suitable antimicrobial scaffolds that also can promote stem cell proliferation and differentiation has been recommended, as well as specific bioactive molecules that enhance angiogenesis and reinnervation. Furthermore, new biocompatible disinfection strategies need to be evaluated to determine the most effective disinfection and preparation of the root canal environment for periapical healing and regrowth of host tissues in the canal by MSCs from periapical vital tissues. These developments in REPs would be a promising step towards the regeneration of destroyed dental tissues not only in immature necrotic teeth but in non-vital mature teeth, which retain the natural dentition and are the ultimate goal of the endodontic practice.

\section{Acknowledgement}

The authors deny any conflicts of interest related to this study.

\section{Conflict of Interest}

No conflict of interest.

\section{References}

1. Jeeruphan T, Jantarat J, Yanpiset K, Suwannapan L, Khewsawai P, et al. (2012) Mahidol study 1: comparison of radiographic and survival outcomes of immature teeth treated with either regenerative endodontic or apexification methods: a retrospective study. J Endod 38: 1330-1336.
2. Banchs F, Trope M (2004) Revascularization of immature permanent teeth with apical periodontitis: new treatment protocol? J Endod 30: 196-200.

3. Diogenes A, Henry MA, Teixeira FB, Hargreaves KM (2013) An update on clinical regenerative endodontics. Endodontic Topics 28: 2-23.

4. Saoud TM, Sigurdsson A, Rosenberg PA, Lin LM, Ricucci D (2014) Treatment of a large cystlike inflammatory periapical lesion associated with mature necrotic teeth using regenerative endodontic therapy. J Endod 40(12): 2081-2086.

5. Saoud TM, Mistry S, Kahler B, Sigurdsson A, Lin LM (2016) Regenerative Endodontic Procedures for Traumatized Teeth after Horizontal Root Fracture, Avulsion, and Perforating Root Resorption. J Endod 42(10): 1476-1482.

6. Lovelace TW, Henry MA, Hargreaves KM, Diogenes A (2011) Evaluation of the delivery of mesenchymal stem cells into the root canal space of necrotic immature teeth after clinical regenerative endodontic procedure. J Endod 37(2): 133-138.

7. Ulusoy AT, Turedi I, Cimen M, Cehreli ZC (2019) Evaluation of Blood Clot, Platelet-rich Plasma, Platelet-rich Fibrin, and Platelet Pellet as Scaffolds in Regenerative Endodontic Treatment: A Prospective Randomized Trial. J Endod 45(5): 560-566.

8. Fouad AF (2017) Microbial Factors and Antimicrobial Strategies in Dental Pulp Regeneration. J Endod 43(9S): S46-S50.

9. Diogenes A, Hrgreaves KM (2017) Microbial Modulation of Stem Cells and Future Directions in Regenerative Endodontics. J Endod 43(9S): S95-S101.

10. Lin LM, Shimizu E, Gibbs JL, Loghin S, Ricucci D (2014) Histologic and histobacteriologic observations of failed revascularization/revitalization therapy: a case report. J Endod 40: 291-295.

11. Verma P, Nosrat A, Kim JR, Price JB, Wang P, et al. (2017) Effect of Residual Bacteria on the Outcome of Pulp Regeneration In Vivo. J Dent Res 96(1): 100-106.

12. Trevino EG, Patwardhan AN, Henry MA, Perry G, Dybdal Hargreaves N, et al. (2011) Effect of irrigants on the survival of human stem cells of the apical papilla in a platelet-rich plasma scaffold in human root tips. J Endod 37(8): 1109-1115.

13. Martin DE, De Almeida JF, Henry MA, Khaing ZZ, Schmidt CE, et al. (2014) Concentration-dependent effect of sodium hypochlorite on stem cells of apical papilla survival and differentiation. J Endod 40(1): 51-55.

14. Galler KM, Krastl G, Simon S, Van Gorp G, Meschi N, et al. (2016) European Society of Endodontology position statement: Revitalization procedures. Int Endod J 49: 717-723.

15. Galler KM, Widbiller M, Buchalla W, Eidt A, Hiller KA, et al. (2016) EDTA conditioning of dentine promotes adhesion, migration and differentiation of dental pulp stem cells. Int Endod J 49(6): 581-590.

16. Galler KM, Buchalla W, Hiller KA, Federlin M, Eidt A, et al. (2015) Influence of root canal disinfectants on growth factor release from dentin. J Endod 41(3): 363-368.

17. Widbiller M, Althumairy RI, Diogenes A (2019) Direct and Indirect Effect of Chlorhexidine on Survival of Stem Cells from the Apical Papilla and Its Neutralization. J Endod 45(2): 156-160.

18. Hoshino E, Kurihara Ando N, Sato I, Uematsu H, Sato M, et al. (1996) In-vitro antibacterial susceptibility of bacteria taken from infected root dentine to a mixture of ciprofloxacin, metronidazole and minocycline. Int Endod J 29: 125-130.

19. Ruparel NB, Teixeira FB, Ferraz CC, Diogenes A (2012) Direct effect of intracanal medicaments on survival of stem cells of the apical papilla. J Endod 38: 1372-1375.

20. Latham J, Fong H, Jewett A, Johnson JD, Paranjpe A (2016) Disinfection Efficacy of Current Regenerative Endodontic Protocols in Simulated Necrotic Immature Permanent Teeth. J Endod 42(8): 1218-1225. 
21. Bose R, Nummikoski P, Hargreaves K (2009) A retrospective evaluation of radiographic outcomes in immature teeth with necrotic root canal systems treated with regenerative endodontic procedures. J Endod 35: 1343-1349.

22. Bukhari S, Kohli MR, Setzer FC, Karabucak B (2016) Outcome of Revascularization Procedure: A Retrospective Case Series. J Endod 42: 1752-1759.
23. Austah O, Joon R, Fath WM, Chrepa V, Diogenes A, et al. (2018) Comprehensive Characterization of 2 Immature Teeth Treated with Regenerative Endodontic Procedures. J Endod 44(12): 1802-1811.

24. Almutairi W, Yassen GH, Aminoshariae A, Williams KA, Mickel A (2019) Regenerative Endodontics: A Systematic Analysis of the Failed Cases. Journal of Endodontics 45(5): 567-577. 